\title{
PROTECCIÓN AL CRÉDITO EN LA GESTIÓN JUDICIAL EN LA PROVINCIA DE CORRIENTES
}

\author{
Jimena Inés Lértora Durand de Cassís, ${ }^{1}$ Luz Gabriela Masferrer ${ }^{2}$ y \\ Augusto Horacio Lorenzo Arduino ${ }^{3}$
}

\section{El crédito: concepto y funcionamiento}

El crédito "es el cambio de un bien presente por un bien futuro". Este concepto podría precisárselo aún más expresando que "el crédito es la transferencia temporal de poder adquisitivo a cambio de la promesa de reembolsar éste más sus intereses en un plazo determinado y en la unidad monetaria convenida.

Este concepto pone de resalto los elementos del crédito, a saber:

1) Implica la transferencia temporal de poder adquisitivo, de un sujeto (el acreedor) a otro (deudor). Generalmente del ahorrista al productor de bienes (empresario). El ahorrista se desprende de poder adquisitivo que no necesita y se lo transfiere temporalmente al productor para que éste pueda destinarlo a la producción de bienes o servicios.

2) Promesa de reembolso del capital más sus intereses. Esto exhibe el elemento "confianza”, puesto que el deudor recibe poder adquisitivo de su acreedor y le "promete" la devolución de ese capital monetario con más el interés pactado. Ese interés es el "precio por el uso de ese capital monetario".

3) Plazo determinado. Aquí aparece el factor "tiempo”, que es intrínseco al crédito y que crea un elemento que está consustanciado con él: el

${ }^{1}$ Abogada, becaria de iniciación tipo B por Res. 1014/12 C.S., adscripta ad-honorem en la asignatura Seminario de Orientación en Derecho Comercial y Empresarial de la Facultad de Derecho de la UNNE.

${ }^{2}$ Profesor Titular con dedicación simple del Seminario de Orientación en Derecho Comercial y Empresarial de la Facultad de Derecho de la UNNE.

${ }^{3}$ Profesor Titular con dedicación exclusiva de la Cátedra B de la asignatura Derecho Comercial, Segundo Curso, e Industrial, de la Facultad de Derecho de la UNNE. 
riesgo. El riesgo en el crédito existe por el hecho de ser tal, esto es, “el cambio de un bien presente por un bien futuro".

4) Unidad monetaria convenida. Este elemento destaca el aspecto "monetario" o "financiero" del crédito. No se trata del cambio de cualquier bien por otro, sino el "cambio de unidades monetarias de dinero". ${ }^{4}$

El crédito se manifiesta en la regulación jurídica en múltiples aspectos, se apoya en la contabilidad comercial que refleja la marcha de los negocios y la verdadera situación del comerciante individual y de las sociedades mercantiles. Éstas, en sus diversos tipos, multiplican la responsabilidad personal y ofrecen garantías que la solvencia individual no podría ofrecer por sí sola; y a través de los títulos de crédito circula y moviliza la riqueza, generando un "mercado" donde se trafica con ellos, entre otros aspectos.

La decisión de otorgamiento de un crédito debe ser adoptada teniendo en cuenta una serie de aspectos como ser: la persona del cliente; la naturaleza de los bienes que integran el patrimonio de dicho cliente; su grado de endeudamiento; su capacidad de pago, sus ingresos y las obligaciones que tiene contraídas; su situación económica financiera; el destino del crédito; las garantías colaterales a exigir; como la modalidad crediticia más conveniente. Analizadas estas cuestiones, la entidad financiera se encuentra en condiciones de otorgar el crédito. ${ }^{5}$

El funcionamiento regular del crédito es un bien jurídico a proteger, ya que cuando el deudor cumple con puntualidad su contraprestación, el intercambio a crédito ha funcionado normalmente y la importancia de este cumplimiento regular repercute en la vida de los negocios ya que estos perduran cuando se da cumplimiento puntual a las obligaciones contraídas. Sin embargo no recibir en la fecha convenida una suma de dinero con la cual se tenía derecho a contar, causa frecuentemente al comercio un perjuicio tan grande como si ya no se pagase más.

El funcionamiento irregular del crédito puede generar conductas abusivas del deudor y aún provocar la insolvencia de éste, con serio perjuicio a los acree-

${ }^{4}$ Villegas, Carlos A. (1985), “Compendio Jurídico, Técnico y Práctico de la Actividad Bancaria I.”, Depalma, Buenos Aires, págs. 50-51.

${ }^{5}$ Villegas, Carlos A., ob. cit., págs. 59-61. 
dores y al interés general. La quiebra puede obedecer a causas preexistentes a la constitución de la relación a crédito, o bien a causas sobrevivientes a ella. En el primer caso, la quiebra se debe a que el crédito ha funcionado en forma anormal, en violación de la ley que preside esta forma perfeccionada del intercambio económico; el deudor ha engañado al acreedor, pues conocía perfectamente su estado de insolvencia; en una palabra, la quiebra es efecto de un verdadero abuso del crédito.

Pero sucede a veces que el desequilibrio patrimonial se produce por causas sobrevinientes, o sea cuando después de haberse constituido la relación a crédito, los bienes existentes en el activo del deudor desaparecen en todo o en parte, o esos bienes se vuelven irrealizables. Cuando el desequilibrio patrimonial es tal que no puede seguir ocultándose, tiene forzosamente que exteriorizarse y entonces se pone de manifiesto el estado de quiebra económica del deudor insolvente.

La persona que toma un crédito, una vez concedido, se puede decir que asume una obligación de pagar un precio por ese crédito. De acuerdo con el art. 725 del Código Civil: "El pago es el cumplimiento de la prestación que hace el objeto de la obligación, ya se trate de una obligación de hacer, ya de una obligación de dar". Entonces, se puede decir que las obligaciones se constituyen para ser cumplidas; tienden a su realización, sea voluntariamente por la parte obligada o por los medios que la ley proporciona para compeler a su cumplimiento.

"El art. 505 del Código Civil contempla los efectos de las obligaciones con relación al acreedor y al deudor. Uno de los efectos de la obligación consiste en dar derecho al acreedor para reclamar el cumplimiento de la prestación. Esta ejecución puede ser obtenida por el sujeto activo de dos maneras:

a) Mediante la ejecución voluntaria por parte del deudor. Es el caso más frecuente. Llegado el momento del vencimiento, el deudor paga, sin necesidad de coacción alguna. Realizada así la prestación, no hay problemas para el derecho.

b) Mediante la ejecución forzada, por medio de la intervención de los tribunales judiciales (art. 505, Cód. Civil). Es la que se opera con intervención judicial, ante el incumplimiento del deudor. El art. 505 del Cód. Civil, contempla dos situaciones al respecto:

1) La ejecución directa de la obligación, vale decir, su cumplimiento in natura, ya sea con intervención del deudor o por terceros. 
2) La ejecución indirecta, por medio de la indemnización de los daños y perjuicios, en cuyo caso el cumplimiento no se obtiene en forma específica sino por medio de su equivalente en dinero. ${ }^{6}$

Es la existencia del incumplimiento, lo que constituye una realidad, que exige brindar herramientas eficaces de recuperación de los créditos que se otorgan, en pos del interés general y de la circulación del dinero en el mercado.

\section{Proceso ejecutivo}

Debido al incumplimiento en materia de créditos, el legislador se vio en la necesidad de regular un procedimiento especial para lograr el recupero de los créditos impagos de manera ágil y abreviada, ya que el factor tiempo es relevante a la hora de rescatar el dinero prestado.

El Código Procesal Civil y Comercial de la provincia de Corrientes, siguiendo las líneas del Código Procesal Civil y Comercial de la Nación, a tal efecto, dedica un libro entero a los procesos de ejecución en el que se encuentra el proceso ejecutivo.

El proceso ejecutivo posee una estructura diferente al proceso ordinario. Es un proceso de limitado ámbito cognitivo, con pruebas limitadas y excepciones específicas. Por ello los requisitos para su procedencia, conforme el art. 520, y en palabras del profesor Arduino, son:

- Títulos que traigan aparejada ejecución: es decir, aquellos títulos mencionados expresamente en el art. 523, que son los que no necesitan ser reconocidos en una sentencia previa para ser ejecutables.

- Obligación jurídicamente exigible: obligación que no se encuentre cancelada, es decir, que no se encuentre paga (art. 725 Cód. Civil), o extinguida por alguna de las formas que autoriza el Código Civil ( art. 724 y ss.) o prescripta (art. 3947)

- Obligación exigible de dar cantidades líquidas de dinero, o fácilmente liquidables: es decir, no sujeta a condición (ver $2^{\circ}$ párrafo art. 520, supuestos en que procede).

${ }^{6}$ Cazeaux, Pedro N. \& Trigo Represas, Félix. A. (2004), Compendio de Derecho de las Obligaciones, Tomo I, Platense, La Plata, pág. 75. 
La liquides es la capacidad que tiene el activo de transformarse rápidamente en dinero.

Entonces, ¿cuáles son los títulos que traen aparejada ejecución? Según el art. 523 del mismo cuerpo legal, ellos son:

1) El instrumento público presentado en forma.

2) El instrumento privado suscripto por el obligado, reconocido judicialmente o cuya firma estuviese certificada por escribano con intervención del obligado y registrada la certificación en el protocolo.

3) La confesión de deuda líquida y exigible prestada ante el juez competente para conocer en la ejecución.

4) La cuenta aprobada o reconocida como consecuencia del procedimiento establecido en el art. 525.

5) La letra de cambio, factura de crédito, vale o pagaré, el cheque y la constancia de saldo deudor en cuenta corriente bancaria, cuando tuvieren fuerza ejecutiva de conformidad con las disposiciones del Código de Comercio o ley especial.

6) El crédito por alquileres o arrendamientos de inmuebles.

7) Los demás títulos que tuvieren fuerza ejecutiva por ley y no estén sujetos a un procedimiento especial.

El juez examinará cuidadosamente el instrumento con que se deduce la ejecución, y si hallare que es de los comprendidos en los arts. 523 y 524 (créditos por expensas comunes), o en otra disposición legal, y que se encuentran cumplidos los presupuestos procesales, librará mandamiento de embargo, observándose el siguiente procedimiento:

1) Con el mandamiento, el oficial de justicia requerirá el pago al deudor. Si no se pagare en el acto el importe del capital reclamado, del estimado por el juez en concepto de intereses y costas, y de la multa establecida por el artículo 528, en su caso, dicho funcionario procederá a embargar bienes suficientes, a su juicio, para cubrir la cantidad fijada en el mandamiento. El dinero deberá ser depositado dentro del primer día hábil siguiente en el banco de depósitos judiciales.

2) El embargo se practicará aun cuando el deudor no estuviese presente, de lo que se dejará constancia.

En este caso, se le hará saber dentro de los tres días siguientes al de la traba. 
Si se ignorase su domicilio, se nombrará al defensor oficial, previa citación por edictos que se publicarán por una sola vez.

3) El oficial de justicia requerirá al propietario de los bienes que manifieste si se encuentran embargados o afectados por prenda u otro gravamen y, en su caso, por orden de qué juez y en qué expediente, y el nombre y domicilio de los acreedores, bajo apercibimiento de lo dispuesto en las leyes sobre la materia. Si el dueño de los bienes no estuviere presente, en la misma diligencia se le notificará que debe formular esta manifestación dentro del plazo para oponer excepciones.

Aunque no se hubiese trabado embargo, la ejecución continuará, pudiendo solicitar el ejecutante la medida cautelar que autoriza el artículo 534 (art. 531).

El art. 542 reza al respecto que la intimación de pago importará la citación para oponer excepciones, debiendo dejarse al ejecutado copia de la diligencia, del escrito de iniciación y de los documentos acompañados.

Las excepciones se propondrán, dentro del tercero día, en un solo escrito, conjuntamente con el ofrecimiento de prueba.

Deberán cumplirse, en lo pertinente, los requisitos establecidos en los artículos 330 y 356, determinándose con exactitud cuáles son las excepciones que se oponen.

La intimación de pago importará, asimismo, el requerimiento para que el deudor dentro del plazo establecido en el párrafo segundo de este artículo, constituya domicilio, bajo apercibimiento de lo dispuesto por el art. 41.

No habiéndose opuesto excepciones dentro del plazo, el juez, sin otra sustanciación, pronunciará sentencia de remate.

El art. 551 del mismo cuerpo legal hace referencia al contenido de la sentencia de remate, que sólo podrá determinar que se lleve la ejecución adelante, en todo o en parte, o su rechazo.

Lo importante en este tipo de proceso expedito, es que el Código (art. 553) permite, tanto al ejecutante como al ejecutado, la opción de promoción de un proceso ordinario posterior, una vez cumplidas las condenas impuestas, cualquiera fuera la sentencia que recaiga en el ejecutivo. 
Conforme el art. 561 es requisito del trámite de cumplimiento de la sentencia de remate, la traba de embargo.

Cuando lo embargado fuese dinero, una vez firme la sentencia o dada la fianza a que se refiere el art. 555, el acreedor practicará liquidación de capital, intereses y costas, de la que se dará traslado al ejecutado, aplicándose, en lo pertinente, las reglas de los artículos 503 y 504. Aprobada la liquidación, se hará pago inmediato al acreedor del importe que de ella resultare.

\section{Principios procesales}

Para el desarrollo de un proceso eficaz, tendiente al recupero del crédito, no se puede dejar de señalar la importancia que los principios procesales juegan en materia de ejecución.

\section{Principio de disposición o dispositivo}

En términos generales se llama principio dispositivo a aquel en cuya virtud se confía a la actividad de las partes tanto el estímulo de la función judicial como la aportación de los materiales sobre los cuales ha de versar la decisión del juez (Palacio, evocando a Schunke y Goldschmidt).

Así, pues, el principal efecto del principio es el de limitar los poderes del juez a la actividad de las partes. Entonces, aquel no habrá de conocer del litigio sino lo que las partes quieran hacerle conocer, de tal manera que debe tener por exactos los hechos no controvertidos.

Va de suyo que las afirmaciones y pruebas aportadas por las partes constituirán los únicos fundamentos de la sentencia, con excepción -claro está- de los casos en que se halla interesado el orden público (Alsina).

¿En qué consiste el principio de disposición?, se pregunta Dorantes Tamayo. Y responde:

Consiste en que las partes impulsan el proceso; el juez no puede actuar sino a petición de estas. Si dichas partes no actúan, el proceso no avanza, e inclusive se puede extinguir por el transcurso de un plazo (caducidad). Por eso se dice que, de acuerdo con este principio, las partes disponen del proceso; de ellas depende que este continúe o no. 
En suma, la iniciación del proceso corresponde exclusivamente a quien ostenta la disposición del derecho o del interés cuya protección solicita. En este mismo sentido, es al titular del derecho a quien corresponde delimitar su pretensión (thema decidendum), la que, finalmente, vinculará y delimitará la potestad del órgano jurisdiccional.

\section{Principio de economía procesal}

Según este principio, el proceso ha de desarrollarse con el menor consumo o mayor reserva de tiempo, energías y costos, "de acuerdo con las circunstancias de cada caso” (Pallares).

Así, pues, su premisa rectora se edifica en la obtención del mejor resultado posible, partiendo de un procedimiento ágil y simple, que se traduzca en un mínimo de esfuerzo, un mínimo de tiempo o un mínimo de costo.

eisner considera como ámbito propio de aplicación del principio, las siguientes proyecciones:

a) la celeridad en los trámites mediante la abreviación en los plazos, la perentoriedad de los términos, la preclusión de las instancias procesales, la limitación de los recursos, la agilización del régimen de notificaciones;

b) la concentración de actos y diligencias mediante la realización simultánea de actos compatibles, la aproximación temporal de las actividades probatorias, la unificación de la personería, la acumulación de acciones y de procesos, el fuero de atracción;

c) proposición conjunta de acciones, defensas, pruebas y recursos esgrimidos en subsidio por razón de eventualidad;

d) la elasticidad de las formas y tipos procesales, que permite adecuar el sistema y modalidad del debate conforme a las necesidades de la litis que se ventila;

e) la implementación de previsiones que conduzcan al abaratamiento de gastos o imposiciones fiscales como forma de evitar dispendios de cualquier tipo. ${ }^{7}$

${ }^{7}$ Borrhwick, Adolfo E.C. (2005), Principios Procesales, Mave, Corrientes, pág. 39. 


\section{Principio de concentración}

Según las reglas del principio de concentración todas las cuestiones litigiosas, o el mayor número posible de las mismas, deben reunirse (concentrarse) en un solo estadio u oportunidad procesal a los fines de ser resueltas a un mismo tiempo en la sentencia definitiva, evitando así que el curso del proceso, en lo principal, se suspenda.

Así entonces, este principio exige que las cuestiones incidentales que surjan en la sustanciación del proceso se reserven para ser resueltas en la sentencia definitiva, a fin de evitar que este se paralice o, lo que es peor, se dilate indefinidamente. La eficacia práctica de estas reglas demanda la reducción al menor número posible de los artículos de previo y especial pronunciamiento, de las excepciones dilatorias y de los recursos con efectos suspensivos.

Para Arazi, la concentración es tan solo un subprincipio (conjuntamente con los de celeridad, eventualidad y saneamiento) del principio de economía procesal.

La consigna es reunir la mayor cantidad posible de actividad procesal en el menor número factible de actos procesales, los cuales, por lo demás, deben regimentarse como muy próximos entre sí.

\section{Principio de congruencia o de correspondencia}

Congruencia es la "Conformidad entre el fallo judicial y las pretensiones de las partes" (Cabanellas). Es decir que la imperatividad del principio de congruencia deberá garantizar por concreta vía recursiva (ordinaria o extraordinaria) la concordancia de identidad entre la sentencia con la pretensión de la demanda y de su contestación (o reconvención), sin que ningún hecho posterior a la discusión escrita pueda modificar los términos en que fue originalmente trabada la cuestión litigiosa. En suma, las sentencias deben ser congruentes no solo consigo mismas, sino también con la litis, tal como quedó entablada por medio de los escritos de demanda, contestación, réplica y dúplica (contrarréplica).

Si bien es en la sentencia donde radica la mayor importancia del principio, debe apuntarse que el mismo también se aplica a autos interlocutorios.

$\mathrm{Y}$ es precisamente el principio en estudio el que impone que sean las partes, exclusivamente, las que determinen el tema a decidir, debiendo el juez, por lo tanto, limitar su pronunciamiento a lo pedido por por aquellas en los actos de demanda y contestación. 


\section{Principio de contradicción, de bilateralidad o de controversia}

El principio de contradicción es una consecuencia inmediata del principio de igualdad de las partes ante la ley procesal, y mediata, de los de inviolabilidad de la defensa en juicio y del debido proceso. Puede traducirse como la existencia institucional de conferirle a las partes iguales oportunidades para el ataque y defensa de sus intereses, regla que no se considera violada si, en su oportunidad, no resulta aprovechada por alguno de aquellas.

Alsina dice que:

bilateralidad no quiere decir que necesariamente deban intervenir las dos partes para que el acto tenga validez, sino que se les haya dado la oportunidad de intervenir. Así, si el demandado no comparece al juicio, la sentencia no será nula porque este se haya seguido en su rebeldía, desde que tuvo oportunidad de intervenir en cualquier momento hasta que la sentencia se dictó.

Implica, en concreto, la necesidad de asegurar el acceso al proceso de toda persona cualquiera que sea su posición, así como de conferir la posibilidad de oír a ambas partes previamente y en relación con cualquier resolución que les afecte. (Asencio Mellado).

Asimismo, tanto la doctrina como los pronunciamientos jurisdiccionales han entendido que las medidas cautelares (que se adoptan sin previa comunicación a la contraria-inaudita parte-) y los procesos monitorios (que invierten la carga del contradictorio y su apertura a la oposición de excepciones después de la sentencia inicial que dicta el juez, verificados los presupuestos en la documentación presentada) no violan las máximas del principio en estudio. Y que tales casos importan tan solo el aplazamiento de la controversia del litigio.

Así, Quintero y Prieto alegan que

Puede pues afirmarse que el principio no tiene ni admite excepción, porque no son excepciones las que se operan cuando la medida cautelar se decreta sin oír a la contraparte. En tal caso, se difiere la posibilidad de la controversia al momento inmediatamente posterior al perfeccionamiento de la misma. Tampoco exceptúa el principio que se limiten taxativamente las excepciones admisibles en un proceso monitorio o ejecutivo si se asegura la posibilidad de una cognición posterior plena (por ejemplo un proceso ordinario poste- 
rior al ejecutivo) o en el que se invierta la iniciativa de la controversia como acaece en el proceso monitorio; igualmente, en el proceso penal, durante la etapa instructoria, la contradicción queda postergada o diferida, pero no suprimida.

De igual modo, a partir de la declaración de la rebeldía del imputado.

Principio de adquisición procesal o de la comunidad de la prueba

Como bien señala Chiovenda, "un derecho importante de las partes se deriva de la circunstancia de que la actividad de ambas pertenece a una relación única que, como tal, se adquiere para el proceso y no para el sujeto que desplegó tal actividad".

Y ello es lo que configura el llamado principio de adquisición procesal o de la comunidad de la prueba, "en cuya virtud -apunta Palacio- los efectos de los actos procesales son susceptibles de beneficiar o de perjudicar a cualquiera de las partes, $y$, por lo tanto, incluso a aquella que solicitó su cumplimiento", agregando que "la vigencia del principio enunciado impide, por ejemplo, que alguna de las partes que produjo una prueba desista luego de ella en razón de serle desfavorable”.

Dos preguntas se formula Dorantes Tamayo: 1) ¿En qué consiste el principio de adquisición procesal? Y responde: “En que las pruebas rendidas por una de las partes pueden ser aprovechadas por la otra, aunque no sea esta la que las haya ofrecido ni rendido". Y 2), ¿en qué se basa? "En que la convicción del juez sobre la existencia o la eficacia de las pruebas no puede ser dividida". ${ }^{8}$

\section{Organización judicial}

A efectos de cumplir eficazmente con la celeridad que desde la norma se impone al procedimiento, resulta imprescindible que la organización judicial se adecue a las necesidades actuales y brinde estructuras judiciales que gestionen

\footnotetext{
${ }^{8}$ Borrhwick, Adolfo E. C., ob. cit., pág. 33.
} 
rápidamente las reclamaciones de los acreedores para que no se vea interrumpido el flujo mercantil.

Es sabido que un alto porcentaje de litigios -que fatigan y exigen al tribunal, generando frustración en los litigantes, jueces y funcionarios-se vinculan con la ejecución de créditos, siendo una preocupación constante la búsqueda de procedimientos más breves y estandarizados que descompriman la gestión del tribunal.

A nivel Nacional la gestión judicial tiene como principal objetivo la modernización total del Poder Judicial. Para esto, la Corte Suprema de Justicia de la Nación creó en diciembre de 2007 la Comisión Nacional de Gestión Judicial, encabezada el presidente del Máximo Tribunal, Ricardo Lorenzetti, e integrada por jueces de todo el país, con el objeto de delinear políticas estratégicas y planes operativos que, mediante la incorporación de nuevas tecnologías y criterios de gestión, impulsan el rediseño de la organización del Poder Judicial.

Se reconoce, entonces, a la gestión judicial como una herramienta de apoyo a la labor de los jueces, así como también la búsqueda de una mejora continua en el trabajo que cotidianamente cumplen magistrados, funcionarios, empleados, auxiliares y abogados; centrándose en algunos ejes temáticos: gestión administrativa organizacional - Rediseño de procesos, Coeficientes de gestión judicial, Firma digital, Notificación electrónica y Expediente digital. (http://www.cij.gov.ar/gestion-judicial.html- consulta 2 de septiembre de 2012)

El Superior Tribunal de Justicia de Corrientes, a fin de optimizar el funcionamiento de los tribunales de la provincia de manera general, ha orientado gran parte de sus metas institucionales a la utilización a pleno de la informática; elaborando progresivas estrategias para alcanzar la "modernización” de la oficina judicial.

A partir de tan claros objetivos se avizoró la concreción de un Programa Integral de Informatización, que abarca todo el Poder Judicial de la Provincia de Corrientes - capital e interior- y todos los fueros. Dicho programa está basado en la implementación de un sistema de información y gestión para el despacho judicial, con el propósito de dar seguimiento a los expedientes y apoyar la gestión de las actuaciones judiciales desde el inicio de su tramitación hasta su finalización, en todo el ámbito jurisdiccional, satisfaciendo las necesidades y requerimientos en materia de registro, gestión, información, control y estadísticas, con el fin de agilizar, automatizar los procesos y optimizar de ese modo la función tribunalicia en respuesta a las demandas del justiciable. 
El Proyecto definido por el Superior Tribunal de Justicia como el más conducente a los objetivos institucionales tiene componentes precisos: la adquisición de un software de Gestión de Juzgados; adecuada capacitación que prepare y familiarice a los usuarios con las nuevas herramientas de trabajo; y la adquisición de tecnología de última generación. (http:// www.juscorrientes.gov.ar/institucional/proyecto/proyecto.php, consulta 2 de septiembre de 2012)

\section{Bibliografía}

Alterini, A. A. (2009), Los contratos de consumo. Derecho Comercial. Doctrinas esenciales. T. II.

Borthiwick, A. E. C. (2005). Principios Procesales. Corrientes: Mario Viera.

Carnota W. (2007), “Meditaciones sobre gestión judicial”. En: Revista La Ley 1/10/2007. La Ley -2007-E-1376.

Cazeaux, P. N. \& Trigo Represas F. A. (2004), Compendio de Derecho de las Obligaciones. La Plata: Platense.

Código Procesal Civil y Comercial de la provincia de Corrientes (2009). Corrientes: Moglia.

De Los Santos, M. A. "La Gestión Judicial de las Causas: Una Visión desde el Derecho Procesal”. Ponencia del XXV Congreso Nacional de Derecho Procesal Comisión de Derecho Procesal Civil.

Díaz de Vivar, E. (2007), «Afianzar la justicia a través de una adecuada gestión judicial», Revista El Derecho del 5/9/2007, nº 11.834, ED.

Donato, J. D. (2008), Juicio Ejecutivo. Buenos Aires: Universidad.

Gandasegui, A. M. J. \& Hernández García (2007), “La modernización de la administración de justicia y la gestión de la calidad”. En: Estudios de Derecho Judicial 105, Consejo General del Poder Judicial de España, Madrid.

Gómez Álvarez, R. (2004), Calidad en la Gestión de la Oficina Judicial. Barcelona: Bosch.

Martorell, E. E. (2010), Tratado de Derecho Comercial. T. II, Contratos comerciales modernos. Buenos Aires: La Ley.

Morello, A. M. (1991), La reforma de la justicia. La Plata, Buenos Aires: Librería Platense y Abeledo Perrot. 
Parody E. \& Gerlero, M. (2006). Herramientas prácticas para una administración eficiente. David Grimberg - Libros Jurídicos.

Piaggi de Vanossi, A. I. (2000), Poder Judicial, desarrollo económico y competitividad en la Argentina. Buenos Aires: Depalma.

Ramiro Sanchez, A. (2002). Demandas de calidad de la Administración Pública: Un derecho a la ciudadanía. Madrid: Dykinson.

Sagues, N. P., "El Poder Judicial y el equilibrio institucional de los poderes del Estado”, ED, 176-800.

Villegas, C. A. (1985), Compendio Jurídico, Técnico y Práctico de la Actividad Bancaria I. Buenos Aires: Depalma.

\section{Fuentes electrónicas:}

Rosales López, Virginia, “Evaluación del Desempeño Judicial, Universidad Complutense de Madrid”. Disponible en: http://www.revecap.com/encuentros/anteriores/viiieea/trabajos/r/pdf/rosales.pdf. http://www.cij.gov.ar/ gestion-judicial.html. (Consulta: $1^{\circ}$ de septiembre de 2012) http:// www.juscorrientes.gov.ar/institucional/proyecto/proyecto.php (Consulta: $1^{\circ}$ de septiembre de 2012). 